\title{
VICISSITUDES E PERSPECTIVAS DO DIREITO À EDUCAÇÃO NO BRASIL: ABORDAGEM HISTÓRICA E SITUAÇÃO ATUAL*
}

\author{
DERMEVAL SAVIANI ${ }^{* *}$
}

\begin{abstract}
RESUMO: Partindo da caracterização do significado do direito à educação como direito social proclamado e considerando-se que a cada direito corresponde um dever, examinam-se as vicissitudes decorrentes do conflito entre o direito à educação e o dever de educar na história da educação brasileira. Em seguida, é analisada a persistência do referido conflito na situação atual para, à guisa de conclusão, considerar-se as perspectivas de solução, o que põe em foco o problema da organização do Sistema Nacional de Educação.
\end{abstract}

Palavras-chave: Direito à educação. Educação brasileira. História da educação. Sistema Nacional de Educação.

\section{Changes AND Perspectives of the Right to EdUCATION \\ IN BRAZIL: HISTORICAL APPROACH AND CURRENT SITUATION}

ABSTRACT: From the characterization of the meaning of the right to education as an affirmed social right and considering that to every right there is a corresponding duty, we examine the changes resulting from the conflict between the right to education and the duty to educate in the history of Brazilian education. Next, the persistence of such conflict in the current situation is analyzed so that, as a conclusion, the perspectives for a solution are considered, which puts the problem of the organization of the National System of Education in the spotlight.

Key words: Right to education. Brazilian education. History of education. National System of Education.

Exposição na mesa redonda "Direito à educação no Brasil e Sistema Nacional de Educação", durante o IV Seminário de Educação Brasileira (SEB), organizado pelo Centro de Estudos Educação e Sociedade (Cedes), na Universidade Estadual de Campinas (Unicamp), em 22 de fevereiro de 2013.

** Faculdade de Educação da Universidade Estadual de Campinas (Unicamp). Campinas (SP) - Brasil. Contato com o autor: <dermevalsaviani@yahoo.com.br> 
VICISSITUDES ET PERSPECTIVES DU DROIT À L'ÉDUCATION AU BRÉSIL: APPROCHE HISTORIQUE ET SITUATION ACTUELLE

RÉSUMÉ: A partir de la caractérisation de la signification du droit à l'éducation en tant que droit social proclamé et en tenant compte que chaque droit correspond à un devoir, on examine les vicissitudes liées au conflit entre le droit à l'éducation et le devoir d'éduquer dans l'histoire de l'éducation brésilienne. Ensuite, la persistance dudit conflit est analysée dans la situation actuelle pour, en guise de conclusion, prendre en considération les perspectives de la solution, ce qui met en relief le problème de l'organisation du système national d'éducation.

Mots-clés: Droit à l'éducation. Éducation brésilienne. Histoire de l'éducation. Système National d'Éducation.

\section{Educação: direito proclamado versus direito real}

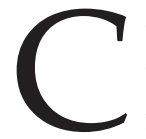

onforme a classificação de Thomas Humphrey Marshall (1967), que já se tornou clássica, distinguem-se os direitos civis, os direitos políticos e os direitos sociais.

Os primeiros são aqueles ligados ao exercício da liberdade individual, como o direito de ir e vir, o livre pensamento, a celebração de contratos e a aquisição e manutenção da propriedade, assim como o acesso aos instrumentos de defesa de todos os direitos, o que se traduz no direito à justiça.

No segundo grupo, o dos direitos políticos, Marshall inclui todos os direitos ligados à participação no poder político, o que envolve a prerrogativa de alguém se tornar governante e de escolher quem governa (direito de votar e ser votado).

Por fim, os direitos sociais correspondem ao acesso de todos os indivíduos ao nível mínimo de bem-estar possibilitado pelo padrão de civilização vigente.

Ainda segundo Marshall, o século XVIII foi a era dos direitos civis. No século XIX vicejaram os direitos políticos e, no século $X X$, chegou a vez dos direitos sociais. Deve-se observar que o livro em que essas questões são apresentadas foi publicado por Marshall em 1949, portanto em plena era keinesiana, quando se forjou o chamado "Estado do bem-estar".

No âmbito da referida classificação, a educação figura como um direito social, sendo mencionada no enunciado do artigo $6^{0}$ da Constituição Federal de 1988, atualmente em vigor, como o primeiro dos direitos sociais: "são direitos sociais a educação, a saúde, o trabalho, a moradia, o lazer, a segurança, a previdência social, a proteção à maternidade e à infância, a assistência aos desamparados, na forma desta Constituição" (VITA, 1989, p. 111). 
No entanto, é preciso considerar que essa classificação tripartite dos direitos individuais resulta um tanto formalista, não espelhando a realidade em suas múltiplas determinações, articulações e contradições. Com efeito, a educação, para além de se constituir em determinado tipo de direito, o direito social, configura-se como condição necessária, ainda que não suficiente, para o exercício de todos os direitos, sejam eles civis, políticos, sociais, econômicos ou de qualquer outra natureza. Isso porque a sociedade moderna, centrada na cidade e na indústria, assumindo a forma de uma sociedade de tipo contratual, substituiu o direito natural ou consuetudinário pelo direito positivo. Isto quer dizer que a sociedade urbano-industrial se baseia em normas escritas. Portanto, a participação ativa nessa sociedade, vale dizer, o exercício dos direitos de todo tipo, pressupõe o acesso aos códigos escritos. Eis porque esse mesmo tipo de sociedade erigiu a escola em forma principal e dominante de educação e advogou a universalização da escola elementar como forma de converter todos os indivíduos em cidadãos, isto é, em sujeitos de direitos e deveres. Tal importância da educação escolar acentua-se ainda mais no contexto atual da chamada "sociedade do conhecimento". Aliás, importa lembrar que, apesar de sua ampla difusão, a denominação de "sociedade do conhecimento" não é apropriada para caracterizar a época atual. Melhor seria, talvez, falar-se em "sociedade da informação". Isso porque conhecimento implica a capacidade de compreender as conexões entre os fenômenos, captar o significado das coisas, do mundo em que vivemos. E hoje parece que quanto mais informações circulam de forma fragmentada pelos mais diferentes veículos de comunicação, mais difícil se torna o acesso ao conhecimento que nos permitiria compreender o significado da situação em que vivemos. Nesse contexto, a escola se torna ainda mais fundamental, porque a ela cabe justamente fornecer os elementos que permitam àquele que tem acesso à informação discriminar as informações falsas das verdadeiras, o que é consistente do inconsistente, o relevante do irrelevante.

Contudo, como sabemos, importa distinguir entre a proclamação de direitos e a sua efetivação. A cada direito corresponde um dever. Se a educação é proclamada como um direito e reconhecido como tal pelo poder público, cabe a esse poder a responsabilidade de prover os meios para que o referido direito se efetive. Eis porque se impôs o entendimento de que a educação é direito do cidadão e dever do Estado. E, para dar cumprimento a esse dever garantindo, em consequência, o direito à educação, os principais países se empenharam, a partir da segunda metade do século XIX, em implantar os respectivos sistemas nacionais de educação, erigidos no caminho efetivo para universalizar a escola básica. Vê-se, pois, que o papel do Sistema Nacional de Educação é dar efetividade à bandeira da escola pública universal, obrigatória, gratuita e laica.

Vejamos, então, como essa questão se pôs historicamente no Brasil no que se refere ao nosso tema, isto é, a educação como direito. 
A proclamação da educação como direito foi se incorporando ao discurso dominante e, progressivamente, foi sendo também consagrada na ordenação legal, culminando com o disposto na Seção I (Da Educação), integrante do Capítulo III (Da Educação, da Cultura e do Desporto) do Título VIII (Da Ordem Social) da Constituição Federal vigente, promulgada em 5 de outubro de 1988 (VITA, op. cit., p. 182-184). E o primeiro dispositivo dessa Seção, o artigo 205, proclama a educação como direito de todos e dever do Estado e da família. Não bastasse a clareza desse enunciado, a norma é reforçada pelos parágrafos $1^{\circ}$ e $2^{\circ}$ do artigo 208, os quais estabelecem que "o acesso ao ensino obrigatório e gratuito é direito público subjetivo" ( $\left(1^{\circ}\right.$ ) e que "o não oferecimento do ensino obrigatório pelo Poder Público, ou sua oferta irregular, importa responsabilidade da autoridade competente" $\left(\S 2^{\circ}\right)$.

No entanto, em que grau o Estado assumiu, ao longo da história do Brasil, o dever correlato de garantir o direito de todos à educação?

\section{O conflito entre o direito à educação e o dever de educar na história do Brasil}

Pode-se considerar que a primeira medida do Estado visando a prover o acesso à educação no Brasil foram os "Regimentos" de D. João III, editados em dezembro de 1548, para orientar as ações do primeiro governador geral do Brasil, Tomé de Souza, que aqui chegou em 1549, acompanhado de quatro padres e dois irmãos jesuítas chefiados por Manuel da Nóbrega. Nesse mesmo ano, os jesuítas deram início à obra educativa centrada na catequese, guiados pela orientação contida nos referidos "Regimentos", cumprindo, pois, um mandato que lhes fora delegado pelo rei de Portugal. Nessa condição cabia à Coroa manter o ensino, mas o Rei enviava verbas para a manutenção e a vestimenta dos jesuítas; não para construções. Então, como relata o padre Manuel da Nóbrega em carta de agosto de 1552, eles aplicavam os recursos no colégio da Bahia "e nós no vestido remediamo-nos com o que ainda do reino trouxemos, porque a mim ainda me serve a roupa com que embarquei... e no comer vivemos por esmolas" (HUE, 2006, p. 68).

Em 1564, a Coroa portuguesa adotou o plano da redízima, pelo qual dez por cento de todos os impostos arrecadados da colônia brasileira passaram a ser destinados à manutenção dos colégios jesuíticos. A partir daí iniciou-se uma fase de relativa prosperidade, dadas as condições materiais que se tornaram bem mais favoráveis. Luiz Alves de Mattos (1958) compara a fase anterior, que ele chama de "período heróico", com o momento subsequente à instituição da "redízima", tomando os aspectos da alimentação; vestuário e calçado; remédios e assistência hospitalar; viagens por terra; viagens por mar; colégios e casas da Companhia de 
Jesus; e os estudos. Em todos esses aspectos, ressalta o contraste entre as dificuldades e privações enfrentadas na primeira fase e as facilidades e conforto usufruídos na segunda.

A educação era financiada com recursos públicos, configurando uma espécie de "educação pública religiosa" (LUZURIAGA, 1959, p. 1). Entretanto, se o ensino então ministrado pelos jesuítas podia ser considerado como público, por ser mantido com recursos públicos e pelo seu caráter de ensino coletivo, ele não preenchia os demais critérios, já que as condições tanto materiais como pedagógicas - isto é: os prédios, assim como sua infraestrutura, os agentes, as diretrizes pedagógicas, os componentes curriculares, as normas disciplinares e os mecanismos de avaliação - se encontravam sob controle da ordem dos jesuítas, portanto, sob domínio privado. O resultado foi que, quando se deu a expulsão dos jesuítas em 1759, a soma dos alunos de todas as instituições jesuíticas não atingia $0,1 \%$ da população brasileira, pois delas estavam excluídas as mulheres (50\% da população), os escravos (40\%), os negros livres, os pardos, filhos ilegítimos e crianças abandonadas (MARCÍLIO, 2005).

Por sua vez, o período seguinte (pedagogia pombalina: 1759-1827) corresponderia aos primeiros ensaios de se instituir uma escola pública estatal. Pelo Alvará de 28 de junho de 1759 determinou-se o fechamento dos colégios jesuítas, introduzindo-se as "aulas régias" a serem mantidas pela Coroa, para o que foi instituído em 1772 o "subsídio literário". As reformas pombalinas se contrapõem ao predomínio das ideias religiosas e, com base nas ideias laicas inspiradas no Iluminismo, institui o privilégio do Estado em matéria de instrução, surgindo, assim, a nossa versão da "educação pública estatal" (LUZURIAGA, 1959). A partir dessa proposta foi baixada a "Carta de Lei" de 10 de novembro de 1772. Por ela foram extintas, no item I, as "coletas" anteriores, substituídas, no item II, por um único imposto:

Nestes Reinos e Ilhas dos Açores e Madeira, de um real em cada canada de vinho; e de
quatro reis em cada canada de aguardente; de cento e sessenta reis por cada pipa de
vinagre: na América e África de um real em cada arrátel de carne da que se cortar nos
açougues; e nelas, e na Ásia de dez reis em cada canada de aguardente das que se fazem
nas terras, debaixo de qualquer nome que se lhe dê, ou venha a dar. (MENDONÇA,
1982, p. 614)

Também no caso das "aulas régias", que se concentravam dominantemente no ensino que corresponderia ao nível secundário, em especial as classes de latim, a responsabilidade do Estado se limitava ao pagamento do salário do professor e às diretrizes curriculares da matéria a ser ensinada. Consequentemente, deixava-se a cargo do próprio professor a provisão das condições materiais relativas ao local, geralmente sua própria casa, e à sua infraestrutura, assim como aos recursos 
pedagógicos a serem utilizados no desenvolvimento do ensino. Essa situação era, ainda, agravada pela insuficiência de recursos, dado que a Colônia não contava com uma estrutura arrecadadora capaz de garantir a obtenção do "subsídio literário" para financiar as "aulas régias".

Com a independência política, foi outorgada por D. Pedro I, em 25 de março de 1824, a primeira Constituição brasileira, que se referiu à educação apenas em seu último artigo, o de número 179. O inciso XXXII desse artigo estipulava que "a instrução primária é gratuita a todos os cidadãos" (CAMPANHOLE; CAMPANHOLE, 1983, p. 653). Decorre daí que, ao fixar o princípio da gratuidade geral do ensino primário, a Constituição estava garantindo a todos os cidadãos brasileiros o direito a esse nível de ensino a expensas do Estado. Mas essa mesma Constituição não fixou como seria efetivada a contrapartida do dever do Estado de assegurar a todos o direito proclamado na Carta Magna do país.

Instalado o Primeiro Império, foi aprovado, em 15 de outubro de 1827, um documento legal que ficou conhecido como lei das escolas de primeiras letras, pois estabelecia, no artigo primeiro: "em todas as cidades, vilas e lugares mais populosos haverão [sic] as escolas de primeiras letras que forem necessárias" (TAMBARA; ARRIADA, 2005, p. 23). Pode-se dizer, entretanto, que essa lei permaneceu letra morta, pois, antes que fosse posta em prática, o Ato Adicional à Constituição do Império, promulgado em 12 de agosto de 1834, conforme estipulado no parágrafo segundo do artigo 10 (CAMPANHOLE; CAMPANHOLE, op. cit.), colocou o ensino primário sob a jurisdição das Províncias, desobrigando o Estado nacional de cuidar desse nível de ensino. Essa medida não deixou de conter um aspecto positivo, pois teve o mérito de facilitar a instalação de escolas, uma vez que já não se fazia necessária a autorização da Assembleia Geral. Com isso, se na sistemática anterior o processo era lento e burocrático, após o Ato Adicional agilizou-se o procedimento para criar e instalar escolas, favorecendo "o processo de difusão da instrução pública" (CASTANHA, 2007, p. 106). Considerando, porém, que as províncias não estavam equipadas nem financeira, nem tecnicamente para promover a difusão do ensino, o resultado foi que atravessamos o século XIX sem que a educação pública fosse suficientemente incrementada. Com isso, o direito à educação gratuita proclamado na Constituição não contou com as condições necessárias para ser realizado.

Durante os 49 anos correspondentes ao Segundo Império, entre 1840 e 1888, a média anual dos recursos financeiros investidos em educação foi de 1,80\% do orçamento do governo imperial, destinando-se, para a instrução primária e secundária, a média de $0,47 \%$. O ano de menor investimento foi o de 1844 , com 1,23\% para o conjunto da educação e $0,11 \%$ para a instrução primária; e o ano de maior investimento foi o de 1888 , com 2,55\% para a educação e $0,73 \%$ para a instrução primária e secundária (CHAIA, 1965). Era, pois, um investimento irrisório. O Estado, portanto, 
não cumpria o seu dever em matéria de educação. Logo, não garantia o direito da população a ter acesso a ela.

Apesar disso, a consciência da importância da educação se expressava na percepção de que "na instrução pública está o segredo da multiplicação dos pães, e o ensino restitui cento por cento o que com ele se gasta", conforme afirmou Almeida Oliveira na sessão de 18 de setembro de 1882 do Parlamento (CHAIA, op. cit., p. 125). E propostas não faltaram. Tavares Bastos, considerando que "não há sistema de instrução eficaz sem o dispêndio de muito dinheiro", propôs em 1870: "Assim como cada habitante concorre para as despesas de iluminação, águas, esgotos, calçadas, estradas e todos os melhoramentos locais, assim contribua para o mais importante deles, a educação dos seus concidadãos, o primeiro dos interesses sociais em que todos somos solidários" (TAVARES BASTOS, 1937, p. 228). A partir daí apresenta um plano de criação de dois tipos de impostos: o local e o provincial. Essa proposta foi retomada por Rodolfo Dantas, em 21 de agosto de 1882, e pela Comissão de Instrução Primária, tendo como relator Rui Barbosa (CHAIA, op. cit.). Contudo, dada a "mania de se quererem os fins sem se empregarem os meios necessários e próprios", conforme declarou Moraes Sarmento em 1850 (idem, ibid., p. 55), resultou que "nenhum país tem mais oradores nem melhores programas; a prática, entretanto, é o que falta completamente", ironizou Agassiz em 1865 (ibid., p. 45). E Rui Barbosa constatava em 1882: “O Estado, no Brasil, consagra a esse serviço apenas 1,99\% do orçamento geral, enquanto as despesas militares nos devoram 20,86\%" (ibid., p. 103). Dessa forma, o sistema nacional de ensino não se implantou e o país foi acumulando um grande déficit histórico em matéria de educação. Continuava, pois, a persistir o conflito entre a proclamação do direito à educação e a sua efetivação.

Nossa segunda Constituição, a primeira do regime republicano, promulgada em 24 de fevereiro de 1891, também se limitou a enunciar apenas um princípio educacional, neste caso, o da laicidade fixado no parágrafo sexto do artigo 72, que assim o enunciou: "Será leigo o ensino ministrado nos estabelecimentos públicos" (CAMPANHOLE; CAMPANHOLE, 1983, p. 587). Claro que o empenho em laicizar a esfera pública, remetendo para o âmbito privado todas as questões de ordem confessional, implicava uma forte responsabilidade do governo central na instituição de um sólido sistema público de ensino, extensivo a todo o território da nação que acabava de se organizar como um Estado republicano. No entanto, isso também não veio a ocorrer. Dado que no Império, que era um regime político centralizado, a instrução popular estava descentralizada, considerou-se que, "a fortiori", na República Federativa, um regime político descentralizado, a educação deveria permanecer descentralizada. Com esse argumento se postergou mais uma vez a organização nacional da instrução popular, mantendo-se o ensino primário sob a responsabilidade das antigas províncias, agora transformadas em Estados federados. Após um período 
de efervescência correspondente à primeira década republicana quando se pretendeu reorganizar a instrução pública por meio de algumas reformas, entre as quais se destacou a reforma paulista de 1892 que instituiu os grupos escolares, a educação entrou em compasso de espera ao prevalecer a "política dos governadores", com o que se impôs o domínio das oligarquias rurais.

Consequentemente, ao longo da Primeira República o ensino permaneceu praticamente estagnado, o que pode ser ilustrado com o número de analfabetos em relação à população total, que se manteve no índice de $65 \%$ entre 1900 e 1920, sendo que o seu número absoluto aumentou de 6.348.869, em 1900, para 11.401.715, em 1920.

A nova Constituição republicana aprovada em 16 de julho de 1934 será a primeira a destinar todo um capítulo à questão educacional. Trata-se do Capítulo II, "Da Educação e da Cultura" (ibid., p. 544-546), que integra o Título V - "Da Família, da Educação e da Cultura". Nesse capítulo podemos identificar os seguintes Princípios Educacionais:

- Universalidade da educação, ao proclamar, no artigo 149, que "a educação é direito de todos";

- Gratuidade do ensino primário (alínea $a$ do § único do artigo 150);

- Obrigatoriedade do ensino primário (alínea a do § único do artigo 150);

- Liberdade de ensino (alínea $c$ do § único do artigo 150);

- Seleção pelo mérito (alínea $e$ do § único do artigo 150);

- Estabilidade dos professores (alínea $f$ do $\S$ único do artigo 150);

- Remuneração condigna do corpo docente (alínea $f$ do $\S$ único do artigo 150);

- Liberdade de cátedra (artigo 155);

- Vinculação orçamentária (artigo 156: “A União e Municípios aplicarão nunca menos de dez por cento, e os Estados e o Distrito Federal nunca menos de vinte por cento, da renda resultante dos impostos, na manutenção e no desenvolvimento dos sistemas educativos");

- Provimento dos cargos do magistério oficial por concurso (artigo 158);

- Vitaliciedade dos cargos do magistério oficial (artigo 158, § 2º);

- Inamovibilidade dos cargos do magistério oficial (artigo 158, § 2º$)$.

A partir da década de 1930, com o incremento da industrialização e urbanização, começa a haver, também, um incremento correspondente nos índices de 
escolarização sempre, porém, em ritmo aquém do necessário à vista dos escassos investimentos. Assim, os investimentos federais em ensino passam de 2,1\%, em 1932, para 2,5 em 1936; os estaduais se reduzem de $15,0 \%$ para $13,4 \%$ e os municipais se ampliam de $8,1 \%$ para $8,3 \%$ no mesmo período (RIBEIRO, 2003). Isso não obstante a Constituição de 1934 ter determinado que a União e os municípios deveriam aplicar nunca menos de $10 \%$ e os estados $20 \%$ da arrecadação de impostos "na manutenção e desenvolvimento dos sistemas educacionais" (art. 156).

A Constituição de 1937 manteve o tópico referente à educação e à cultura, no qual, entretanto, os princípios enunciados na Carta de 1934 ou não se fazem presentes ou são relativizados. Assim, o caráter público da educação é fortemente relativizado ao se definir, no artigo 129, que "o ensino pré-vocacional e profissional destinado às classes menos favorecidas é, em matéria de educação, o primeiro dever do Estado". E, mesmo nessa área, se estipula que a ação do Estado incluirá o subsídio à "iniciativa dos Estados, dos Municípios e dos indivíduos ou associações particulares e profissionais", definindo-se que "é dever das indústrias e dos sindicatos econômicos criar, na esfera de sua especialidade, escolas de aprendizes, destinadas aos filhos de seus operários ou de seus associados" (CAMPANHOLE; CAMPANHOLE, 1983, p. 443).

O enunciado do artigo 130 contempla os princípios da gratuidade e obrigatoriedade do ensino primário, mas esses princípios são relativizados quando se afirma, no mesmo artigo, que "a gratuidade, porém, não exclui o dever de solidariedade dos menos para com os mais necessitados; assim, por ocasião da matrícula, será exigida aos que não alegarem, ou notoriamente não puderem alegar escassez de recursos, uma contribuição módica e mensal para a caixa escolar".

Foi mantido o princípio da liberdade de ensino quando se determinou, no artigo 128, que "a arte, a ciência e o seu ensino são livres à iniciativa individual e à de associações ou pessoas coletivas, públicas e particulares". Quanto aos demais princípios contemplados na Constituição de 1934 (seleção pelo mérito, estabilidade dos professores, remuneração condigna do corpo docente, liberdade de cátedra, vinculação orçamentária, provimento dos cargos do magistério oficial por concurso, vitaliciedade e inamovibilidade dos cargos do magistério oficial), a Carta de 1937 silenciou inteiramente.

Sob a égide da Constituição do Estado Novo surgiram as "leis orgânicas do ensino", optando-se, assim, por organizar a educação nacional por partes, e não como um sistema integrado, regulado por uma lei unificada. Dando cumprimento à norma constitucional que estabelecia como dever prioritário do Estado o ensino profissional, as leis orgânicas regularam, além dos ensinos secundário e primário, os ensinos industrial, comercial e normal, complementados pela criação do Sistema 
Nacional de Aprendizagem Industrial (Senai) e do Sistema Nacional de Aprendizagem Comercial (Senac). No entanto, a vinculação orçamentária foi retirada na Constituição de 1937 que instituiu o Estado Novo.

A Constituição de 1946, promulgada em 18 de setembro, retomou, de certo modo, a sistemática iniciada com a Constituição de 1934 e interrompida com o advento do Estado Novo. Com efeito, ela reservou no Título VI, “Da Família, da Educação e da Cultura", o Capítulo II à educação e à cultura, onde contemplou todos os princípios previstos na Constituição de 1934 (ibid., p. 256-257). Além disso, essa Carta retomou a vinculação orçamentária, fixando em $20 \%$ a obrigação mínima dos estados e municípios e 10\% da União. No entanto, em 1955 tínhamos os seguintes índices: União, 5,7\%; estados, 13,7\%; municípios, 11,4\%.

A Constituição promulgada pelo regime militar em 24 de janeiro de 1967 tratou da educação no Título IV, "Da Família, da Educação e da Cultura" (ibid., p. 179180). Quanto aos Princípios Educacionais, observa-se que houve uma relativização do princípio da gratuidade quando, no Inciso III do parágrafo $3^{\circ}$, do artigo 168 , se afirmou: "sempre que possível, o Poder Público substituirá o regime de gratuidade pelo de concessão de bolsas de estudo, exigido o posterior reembolso no caso de ensino de grau superior". Além disso, essa Carta não contemplou os princípios da Seleção pelo mérito, Estabilidade dos professores, Remuneração condigna do corpo docente, Vinculação orçamentária, Vitaliciedade e Inamovibilidade dos cargos.

A Constituição de 1969, formalmente Emenda Constitucional n. 1, de 17 de novembro de 1969, baixada pela Junta Militar que assumiu o governo entre a doença de Costa e Silva e a posse do general Emílio Garrastazu Médici, manteve os mesmos dispositivos relativos à educação anteriormente indicados, introduzindo apenas algumas mudanças de redação (CAMPANHOLE; CAMPANHOLE, 1983, p. 75-76).

No entanto, a Constituição do regime militar, baixada em 1967, e a Emenda de 1969 voltaram a excluir a vinculação orçamentária. Constata-se, então, que o orçamento da União para educação e cultura caiu de 9, 6\% em 1965 (RIBEIRO, 2003) para 4,31\% em 1975 (VIEIRA, 1983).

A Constituição de 5 de outubro de 1988 dedica uma seção específica à educação (Seção I do Capítulo III, “Da Educação, da Cultura e do Desporto”), onde se estipula como base do ensino os princípios da "igualdade de condições para o acesso e permanência na escola"; "liberdade de aprender, ensinar, pesquisar e divulgar o pensamento, a arte e o saber"; "pluralismo de ideias e de concepções pedagógicas, e coexistência de instituições públicas e privadas de ensino"; "gratuidade do ensino público em estabelecimentos oficiais"; "valorização dos profissionais do ensino, garantindo, na forma da lei, planos de carreira para o magistério público, com piso salarial profissional e ingresso exclusivamente por concurso público de provas e 
títulos, assegurado regime jurídico único para todas as instituições mantidas pela União"; "gestão democrática do ensino público, na forma da lei" e "garantia de padrão de qualidade" (art. 206, incisos I a VII, apud VITA, 1989, p. 182).

Além desses enunciados, explicitamente nomeados como princípios, essa mesma Constituição estatui a autonomia universitária (art. 207); mantém os princípios da universalidade da educação; gratuidade e obrigatoriedade do ensino fundamental; liberdade de ensino; e restabelece a vinculação orçamentária, elevando os percentuais que passam para $18 \%$, no caso da União, e para $25 \%$ nos casos dos estados, Distrito Federal e municípios (art. 212).

No entanto, como o texto constitucional estabelece esses percentuais mínimos em relação à "receita resultante de impostos", além do desrespeito contumaz à norma estabelecida na Carta Magna, encontrou-se, especialmente a partir do governo FHC, outro mecanismo de burlar essa exigência. Passou-se a criar novas fontes de receita, nomeando-as, porém, não com a palavra "imposto", mas utilizando o termo "contribuição", como são os casos da Contribuição para o Financiamento da Seguridade Social (Cofins), Contribuição Provisória sobre Movimentação Financeira (CPMF) e Contribuição sobre Intervenção no Domínio Econômico (Cide). A essas receitas, como não recebem o nome de impostos, não se aplica a vinculação orçamentária constitucional dirigida à educação.

\section{Persistência do conflito na situação atual}

Dada essa histórica resistência a investir na educação, o Brasil chegou ao final do século XX sem resolver um problema que os principais países, inclusive nossos vizinhos Argentina, Chile e Uruguai, resolveram na virada do século XIX para o XX: a universalização do ensino fundamental, com a consequente erradicação do analfabetismo. Para enfrentar esse problema, a Constituição de 1988 previu, nas disposições transitórias, que o poder público - nas suas três instâncias (a União, os estados e os municípios) - deveria, pelos dez anos seguintes, destinar $50 \%$ do orçamento educacional para essa dupla finalidade. Isso não foi feito. Quando esse prazo estava vencendo, o governo criou o Fundo de Manutenção e Desenvolvimento do Ensino Fundamental e de Valorização do Magistério (Fundef) com prazo de mais dez anos para essa mesma finalidade; e a LDB, por sua vez, instituiu a década da educação; seguiu-se a aprovação, em 2001, do Plano Nacional de Educação, que também se estenderia por dez anos. No final de 2006, ao se esgotarem os dez anos do prazo do Fundef, foi instituído o Fundo de Manutenção e Desenvolvimento da Educação Básica e de Valorização dos Profissionais da Educação (Fundeb), com prazo de 14 anos, ou seja, até 2020. Agora, quando mais da metade do tempo do PNE já passou, vem um novo Plano - o Plano de Desenvolvimento da Educação (PDE) - estabelecer 
um novo prazo, desta vez de 15 anos, projetando a solução do problema para 2022. Nesse diapasão, já podemos conjecturar sobre um novo Plano que será lançado em 2022, prevendo, quem sabe, mais vinte anos para resolver o mesmo problema. Vê-se, pois, que o direito à educação segue sendo proclamado, mas o dever de garantir esse direito continua sendo protelado.

No contexto atual a essa tendência protelatória é adicionado outro ingrediente, representado pela demissão do Estado que alimenta o recurso à filantropia e ao voluntariado, transferindo para a sociedade civil, em suas diferentes instâncias, a responsabilidade pela educação. Nos últimos vinte anos tal tendência vem se manifestando no fortalecimento da iniciativa privada e envolvendo uma franca privatização do ensino superior, dominado por grandes conglomerados com participação internacional por meio de ações na Bolsa de Valores; passa pelas parcerias públicoprivadas, as famosas PPPs; pela conversão de dirigentes e ex-dirigentes da educação pública em consultores de grupos privados; pela adoção por governos municipais e estaduais de material didático produzido por grupos privados como COC, Anglo, Positivo, Objetivo, entre outros; e chega à responsabilização de toda a sociedade pela educação básica.

No Governo de Fernando Henrique Cardoso (1995-2002), o apelo ao voluntariado teve sua manifestação mais conspícua num folheto publicitário distribuído pelo MEC para a Campanha "Acorda Brasil. Está na hora da escola", lançado em março de 1995, portanto no início da gestão Paulo Renato. Nesse folheto apela-se aos cidadãos para patrocinar palestras, seminários e cursos de atualização nas escolas; para doar livros e assinaturas de jornais e revistas, materiais e recursos didáticos; prestar auxílio administrativo à escola; ministrar aulas de reforço para crianças com dificuldade de aprendizagem. Tudo se passa como se a educação tivesse deixado de ser assunto de responsabilidade pública a cargo do Estado, transformando-se em questão da alçada da filantropia. No Governo Lula esse papel está sendo desempenhado pelo Movimento "Todos pela Educação", de iniciativa do empresariado paulista, que, a atestar a vigência da promiscuidade público-privada, veio a dar nome ao decreto que instituiu, em abril de 2007, o Plano de Desenvolvimento da Educação (PDE), o qual sintetiza a principal política educacional em vigor atualmente no Brasil.

Dir-se-ia que essa tendência do Poder Público em transferir a responsabilidade pela educação para o conjunto da sociedade, guardando para si o poder de regulação e de avaliação das instituições e dos resultados do processo educativo, operou uma inversão no princípio constitucional que considera a educação "direito de todos e dever do Estado", passando-se a considerar a educação pública como dever de todos e direito do Estado. Por esse caminho será acentuada a equação perversa que marca a política educacional brasileira atual, assim caracterizada: filantropia + protelação + fragmentação + improvisação = precarização geral do ensino no país. 


\section{Conclusão: o Sistema Nacional de Educação como garantia do direi- to à educação}

A organização do sistema nacional de ensino foi a via adotada pelos principais países, a exemplo da Europa e também de nossos vizinhos Argentina, Chile e Uruguai, para assegurar o direito à educação às suas respectivas populações. O Brasil não seguiu esse caminho e, por isso, foi ficando para trás ao invocar recorrentemente, em especial na discussão dos projetos da primeira e da atual LDB, o argumento de que a adoção do regime federativo seria um fator impeditivo da instituição de um Sistema Nacional de Educação. Contrariamente a essa argumentação, eu diria que a forma própria de se responder adequadamente às necessidades educacionais de um país organizado sob o regime federativo é exatamente por meio da organização de um Sistema Nacional de Educação. Isso porque, sendo a Federação a unidade de vários estados que, preservando suas respectivas identidades, intencionalmente se articulam tendo em vista assegurar interesses e necessidades comuns, ela postula o sistema nacional. Este, no campo da educação, representa a união intencional dos vários serviços educacionais que se desenvolvem no âmbito territorial dos diversos entes federativos que compõem o Estado federado nacional.

Na construção do Sistema Nacional de Educação e na efetivação do Plano Nacional de Educação, deve-se levar em conta o regime de colaboração entre a União, os estados, o Distrito Federal e os municípios, conforme disposto na Constituição Federal, efetuando uma repartição das responsabilidades entre os entes federativos, todos voltados para o mesmo objetivo de assegurar o direito de cada brasileiro, provendo uma educação com o mesmo padrão de qualidade a toda a população.

Na repartição das responsabilidades os entes federativos concorrerão na medida de suas peculiaridades e de suas competências específicas consolidadas pela tradição e confirmadas pelo arcabouço jurídico. Assim, as normas básicas que regularão o funcionamento do sistema serão de responsabilidade da União, consubstanciadas na Lei de Diretrizes e Bases da Educação Nacional e no Plano Nacional de Educação, traduzidas e especificadas pelas medidas estabelecidas no âmbito do Conselho Nacional de Educação. Os estados e o Distrito Federal poderão expedir legislação complementar, adequando as normas gerais a eventuais particularidades locais. Não incluo aqui os municípios porque a Constituição Federal não lhes confere a competência para legislar em matéria de educação. Veja-se o artigo 30 da Constituição que trata das competências dos municípios. O inciso VI assim reza: "manter, com a cooperação técnica e financeira da União e do Estado, programas de educação pré-escolar e de ensino fundamental" (VITA, 1989, p. 122).

O financiamento do sistema será compartilhado pelas três instâncias, conforme o regime dos fundos de desenvolvimento educacional. Assim, além do Fundeb, 
que deverá ser aperfeiçoado, cabe criar também um Fundo de Manutenção da Educação Superior (Fundes). Se, no caso do Fundeb, a maioria dos recursos provém de estados e municípios, cabendo à União um papel complementar, em relação ao Fundes a responsabilidade da União será dominante, entrando os estados apenas em caráter complementar, limitando-se aos casos de experiência já consolidada na manutenção de universidades.

A formação de professores, a definição da carreira e as condições de exercício docente constituem algo que não pode ser confiado aos municípios. Isso não é possível, de fato, porque a grande maioria dos municípios não preenche os requisitos para atuar nesse âmbito. E também não é possível, de direito, porque a própria LDB, pelo inciso V do artigo 11, os impede de atuar na formação de professores, uma vez que somente poderão se dedicar a outros níveis de ensino ulteriores ao fundamental "quando estiverem atendidas plenamente as necessidades de sua área de competência e com recursos acima dos percentuais mínimos vinculados pela Constituição Federal à manutenção e desenvolvimento do ensino". Dado que a formação de professores ocorre, como regra, no nível superior e, transitoriamente, no nível médio, escapa aos municípios essa atribuição. Segue-se que as questões relativas ao magistério constituem matéria de responsabilidade compartilhada entre União e estados.

A responsabilidade principal dos municípios incidirá sobre a construção e conservação dos prédios escolares e de seus equipamentos, assim como sobre a inspeção de suas condições de funcionamento, além, é claro, dos serviços de apoio como merenda escolar, transporte escolar, entre outros. Efetivamente, são esses os aspectos em que os municípios têm experiência consolidada. Os municípios, de modo geral, estão equipados para regular, por uma legislação própria, a ocupação e uso do solo. Rotineiramente, cabe às prefeituras examinar projetos relacionados aos mais variados tipos de construção, verificando sua adequação à finalidade da obra a ser construída. Assim, quer se trate de moradias, de hospitais, de restaurantes, de igrejas, entre outras obras, o órgão municipal irá verificar se o projeto atende às características próprias do tipo de construção preconizado à luz da finalidade que lhe caberá cumprir. Ora, é evidente que, em se tratando das escolas, as prefeituras também podem cumprir, sem qualquer dificuldade, essa função.

Poder-se-ia argumentar que esse tratamento dado aos municípios reduziria sua importância e o grau de sua autonomia. Deve-se frisar, contudo, que a diferença de graus de autonomia não significa redução de importância para as instâncias que detêm menor autonomia. É comum afirmar-se que o município é a instância mais importante, pois é aí onde, concretamente, vivem as pessoas. Desse ponto de vista, o estado e a União se configuram como instâncias abstratas, já que sua realidade se materializa, de fato, no recorte dos municípios. Ora, mas se assim é, então está 
claro que a configuração dos estados e da União, sua estrutura, sua organização e administração são operadas por indivíduos concretos, cidadãos reais, ou seja, os habitantes dos municípios. Portanto, se a autonomia se concentra mais nos estados do que nos municípios é porque, no âmbito do estado, ela se exercita em relação a todos os municípios que o integram e não apenas por parte de cada município em confronto com os demais. O mesmo se diga da União, cuja autonomia se exerce em relação a todas as unidades federativas e não apenas na contraposição entre elas. Em última instância, são os munícipes que atuam simultaneamente nas três instâncias que, obviamente, se fortalecem reciprocamente, na medida em que se estreitam os laços de articulação que as unem em torno de propósitos e interesses comuns.

Não cabe, pois, postularem-se autonomias artificiais, enunciando discursos que não correspondem à realidade efetiva. No caso da educação, para ficar no nosso campo de interesse, o discurso da autonomia local ou regional com as normas decorrentes teve efeitos bem diferentes do proclamado, o que pode ser constatado tanto no plano diacrônico, isto é, historicamente, como no plano sincrônico, ou seja, nas condições atuais. Assim, por exemplo, a historiografia registra que o Ato Adicional de 1834 teve o propósito de descentralizar a instrução primária, conferindo maior grau de autonomia às províncias, o que lhes permitiria maior margem de criatividade e adequação da instrução às suas necessidades e características específicas. Mas não foi propriamente isso o que ocorreu. A tendência que prevaleceu foi que, embora as reformas do governo imperial tivessem validade apenas para o chamado município neutro, isto é, a cidade do Rio de Janeiro, capital do Império, as províncias acabavam por tomá-las como modelo na organização da instrução pública nos respectivos territórios, reproduzindo as mesmas medidas adotadas pelo governo central.

A partir de um estudo minucioso das fontes primárias representadas pela legislação educacional do Império brasileiro e pelos relatórios dos presidentes de províncias e dos inspetores de instrução pública, André Castanha analisou os currículos da escola primária, os métodos de ensino, os castigos e prêmios, os livros e manuais didáticos, o perfil dos professores, as condições para o exercício do magistério, as escolas normais e os alunos-mestres (CASTANHA, 2007), constatando significativas semelhanças nesses diferentes aspectos nas províncias estudadas, $\mathrm{o}$ que se explica pelo fato de que "as províncias seguiram as orientações dos centros mais desenvolvidos, especialmente da Corte e Província do Rio de Janeiro, reproduzindo nas respectivas legislações provinciais os mesmos princípios e dispositivos do centro irradiador" (ibid., p. 510). E isso vem se repetindo, em maior ou menor grau, até os dias atuais.

A melhor forma de fortalecer as instâncias locais não é, necessariamente, conferir-lhes autonomia, deixando-as, de certo modo, à própria sorte. Na verdade, 
a melhor maneira de respeitar a diversidade dos diferentes locais e regiões é articulá-los no todo, e não isolá-los. Isso porque o isolamento tende a fazer degenerar a diversidade em desigualdade, cristalizando-a pela manutenção das deficiências locais. Inversamente, articuladas no sistema, enseja-se a possibilidade de fazer reverter as deficiências, o que resultará no fortalecimento das diversidades em benefício de todo o sistema. Por isso, considero equivocada a política de municipalização do ensino fundamental. Seu efeito está sendo exacerbar as desigualdades de vez, o que leva ao seguinte resultado: municípios pobres têm uma educação pobre, municípios remediados, uma educação remediada e municípios ricos, uma educação de melhor qualidade.

Em suma, o Sistema Nacional de Educação integra e articula todos os níveis e modalidades de educação com todos os recursos e serviços que lhes correspondem, organizados e geridos, em regime de colaboração, por todos os entes federativos sob coordenação da União. Fica claro, pois, que a repartição das atribuições não implica a exclusão da participação dos entes aos quais não cabe a responsabilidade direta pelo cumprimento daquela função. Eles participarão por meio dos respectivos colegiados, acompanhando e apresentando subsídios que venham a tornar mais qualificadas as decisões tomadas. E assumirão responsabilidades diretas nos aspectos que lhes correspondem, por meio das Secretarias e Conselhos Estaduais de Educação e das Secretarias e Conselhos Municipais de Educação, sempre que tal procedimento venha a concorrer para a flexibilização e maior eficácia da operação do sistema sem prejuízo, evidentemente, do comum padrão de qualidade que caracteriza o Sistema Nacional de Educação.

Devemos caminhar resolutamente na via da construção de um verdadeiro Sistema Nacional de Educação, isto é, um conjunto unificado que articula todos os aspectos da educação no país inteiro, com normas comuns válidas para todo o território nacional e com procedimentos também comuns, visando a assegurar educação com o mesmo padrão de qualidade a toda a população do país. Não se trata, portanto, de se entender o Sistema Nacional de Educação como um grande guarda-chuva com a mera função de abrigar 27 sistemas estaduais de ensino, incluído o do Distrito Federal, o próprio sistema federal de ensino e, no limite, 5.570 sistemas municipais de ensino, supostamente autônomos entre si. Se for aprovada uma proposta nesses termos, o Sistema Nacional de Educação se reduzirá a uma mera formalidade, mantendo-se, no fundamental, o quadro de hoje com todas as contradições, desencontros, imprecisões e improvisações que marcam a situação atual, de fato avessa às exigências da organização da educação na forma de um sistema nacional.

É preciso, pois, instituir um sistema nacional em sentido próprio que, portanto, não dependa das adesões autônomas e "a posteriori" de estados e municípios. Sua adesão ao sistema nacional deve decorrer da participação efetiva na sua 
construção, submetendo-se, em consequência, às suas regras. Não se trata, pois, de conferir a estados e municípios, a partir dos respectivos sistemas autônomos, a prerrogativa de aderir ou não a este ou àquele aspecto que caracteriza o sistema nacional. E não cabe invocar a cláusula pétrea da Constituição referente à forma federativa de Estado com a consequente autonomia dos entes federados. Isso porque o Sistema Nacional de Educação não é do governo federal, mas é da Federação, portanto, dos próprios entes federados que o constroem conjuntamente e participam, também em conjunto, de sua gestão.

Concebido na forma indicada e efetivamente implantado o Sistema Nacional de Educação, seu funcionamento será regulado pelo Plano Nacional de Educação, ao qual cabe, a partir do diagnóstico da situação em que o sistema opera, formular as diretrizes, definir as metas e indicar os meios pelos quais as metas serão atingidas no período de vigência do plano definido, pela nossa legislação, em dez anos.

Se o caminho que acabo de apontar for efetivamente seguido, o direito à educação estará assegurado a todos os brasileiros. Entretanto, se novamente enveredarmos por disputas localistas, perdendo de vista o objetivo maior da construção de um sistema educacional sólido, consistente, regido por um mesmo padrão de qualidade que torne a educação pública acessível a toda a população do país sem uma única exceção, mais uma vez estaremos adiando a solução do problema educativo. E as perspectivas não serão nada animadoras, pois um país que não cuida seriamente da educação de suas crianças e jovens, propiciando às novas gerações uma formação adequada, está cassando o próprio futuro.

\section{Referências}

CAMPANHOLE, A.; CAMPANHOLE, H.L. Constituições do Brasil. 6. ed. São Paulo: Atlas, 1983.

CASTANHA, A.P. O Ato Adicional de 1834 e a instrução elementar no Império: descentralização ou centralização? 2007. 2 v. Tese (Doutorado em Educação) - Universidade Federal de São Carlos, São Carlos. p. 404-494.

CHAIA, J. Financiamento escolar no segundo império. Marília: Faculdade de Filosofia, Ciências e Letras, 1965. p. 129-131.

HUE, S.M. Primeiras cartas do Brasil (1551-1555). Rio de Janeiro: Zahar, 2006.

LUZURIAGA, L. História da educação pública. São Paulo: Nacional, 1959. p. 5-22.

MARCÍLIO, M.L. História da escola em São Paulo e no Brasil. São Paulo: Imprensa Oficial, 2005. 
MARSHALL, T.H. Cidadania, classe social e status. Rio de Janeiro: Zahar, 1967.

MATTOS, L.A. Primórdios da educação no Brasil. Rio de Janeiro: Aurora, 1958. p. 275-297.

MENDONÇA, M.C. Aula do commercio. Rio de Janeiro: Xerox do Brasil, 1982.

RIBEIRO, M.L.S. História da educação brasileira. 19. ed. Campinas: Autores Associados, 2003.

TAMBARA, E.; ARRIADA, E. (Org.). Coletânea de leis sobre o ensino primário e secundário no período imperial brasileiro: Lei de 1827; Reforma Couto Ferraz - 1854; Reforma Leôncio de Carvalho - 1879. Pelotas: Seiva, 2005.

TAVARES BASTOS, A.C. A Província. 2. ed. São Paulo: Nacional, 1937.

VIEIRA, E.A. Estado e miséria social no Brasil: de Getúlio a Geisel. São Paulo: Cortez, 1983.

VITA, Á. Nossa Constituição. São Paulo: Ática, 1989.

Recebido em 2 de junho de 2013.

Aprovado em 17 de julho de 2013. 